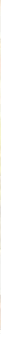

\title{
O enxaimel como patrimônio histórico: perspectiva arquitetônica de uma edificação colonial em Itapiranga/SC
}

The enxaimel as historical patrimony: architectural perspective of a colonial building in Itapiranga/SC

El enxaimel como patrimonio historico: perspectiva arquitectónica de una edificación colonial em Itapiranga/SC

\author{
Douglas Orestes Franzen \\ Professor Doutor, Uceff Itapiranga \\ douglas@uceff.edu.br \\ Claudine Machado Badalotti \\ Professora Mestre \\ Uceff Itapiranga \\ Gabriel Chaves \\ gabrielchaves96@hotmail.com
}

Acadêmico do Curso de Arquitetura e Urbanismo. Uceff Itapiranga 


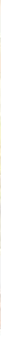

RESUMO

A identidade cultural é constituída por vínculos simbólicos que se manifestam nas tradições, nas vivências, nas práticas simbólicas, na memória, nas relações sociais e na interação da sociedade com o meio. Nessa dimensão o patrimônio se constitui como uma representação dessa identidade cultural, sendo a arquitetura um elemento de manifestação da identidade e da herança histórica. O objetivo do texto é relacionar o patrimônio histórico materializado pela arquitetura enxaimel numa região de colonização germânica através da análise tipológica de uma residência presente na paisagem de Itapiranga/SC.

PALAVRAS-CHAVE: Itapiranga, enxaimel, patrimônio, identidade. 


\section{INTRODUÇÃO}

O município de Itapiranga teve seu processo de colonização iniciado em 1926. Tendo sido denominada inicialmente de Colônia Porto Novo, a colonização se estruturou sob a dinâmica da identidade étnica germânica e na confessionalidade católica. Essa peculiaridade configurou uma identidade histórica, aspecto que se demonstra atualmente em diversos aspectos sociais e culturais.

Um desses aspectos se materializa na arquitetura através das edificações históricas que se mantêm na paisagem local Percebem-se em Itapiranga diversas tipologias arquitetônicas, que comumente são denominadas de arquitetura colonial, que refletem a influência da cultura germânica na identidade local. Nesse sentido, a arquitetura enxaimel apresenta diversos registros no espaço local.

Atualmente em Itapiranga há inúmeras edificações que manifestam a arquitetura enxaimel, tanto na paisagem urbana quanto rural. Essa realidade potencializa a discussão acerca da dimensão patrimonial desse elemento arquitetônico, servindo de suporte para discussões patrimoniais, de identidade cultural, de práticas de turismo, de desenvolvimento urbano e rural e de planejamento dos espaços locais.

Nesse sentido, o texto objetiva analisar uma edificação em Itapiranga e relacioná-la com a discussão acerca da identidade histórica e da dimensão patrimonial que a arquitetura enxaimel representa tanto para a constituição de políticas culturais e de turismo, bem como, na formatação de uma paisagem urbana e rural. Dessa forma, busca-se vincular a arquitetura com a história local e consequentemente com a dimensão do patrimônio arquitetônico. $O$ texto pretende servir de suporte para uma discussão das tipologias arquitetônicas coloniais de Itapiranga, apresentando uma análise histórica e sua relação com a arquitetura.

\section{A COLONIZAÇÃO DE ITAPIRANGA}

O projeto de colonização Porto Novo foi idealizado pela Sociedade União Popular, denominada em alemão de Volksverein, instituição que coordenou a implantação de outras colônias alemãs no Rio Grande do Sul, vinculado aos Padres Jesuítas, com o objetivo de implantar no extremo oeste de Santa Catarina uma nova fronteira agrícola e social. O empreendimento foi financiado pela Cooperativa de Crédito Sparkasse, e fundado oficialmente no ano de 1926. Já no ano de 1928, a colonização recebeu o nome de Itapiranga, atual nome do município, gerando mais tarde a emancipação dos municípios de Tunápolis e São João do Oeste.

A Volksverein für die deutschen Katholiken von Rio Grande do Sul não era necessariamente uma empresa de colonização. Era, na verdade, uma entidade associativa fundada para dar assistência à população de descendência alemã e católica no Sul do Brasil. Essa associação chegou a ter no período da Primeira Guerra Mundial cerca de oito mil associados.

A característica do empreendimento Porto Novo era de aceitar somente migrantes que fossem de origem germânica e católica. Nesse sentido, famílias originárias das colônias do Rio Grande do Sul e de Santa Catarina compraram terras nessa colônia em busca de novas fronteiras agrícolas, onde as terras já estavam subdivididas e esgotadas. Da mesma forma, adquiriram terras em Porto Novo, imigrantes que fugiam das duras condições de vida em vilarejos europeus, expulsos pelas atrocidades da guerra, pela perseguição étnica-política, ou pelas péssimas condições de vida e de trabalho lá existentes.

O processo de fundação da colônia Porto Novo promoveu a transferência de um local para outro de uma bagagem cultural alicerçada em sujeitos através de uma estrutura socioeconômica e cultural que esses sujeitos trataram de transportar de seu local de origem 


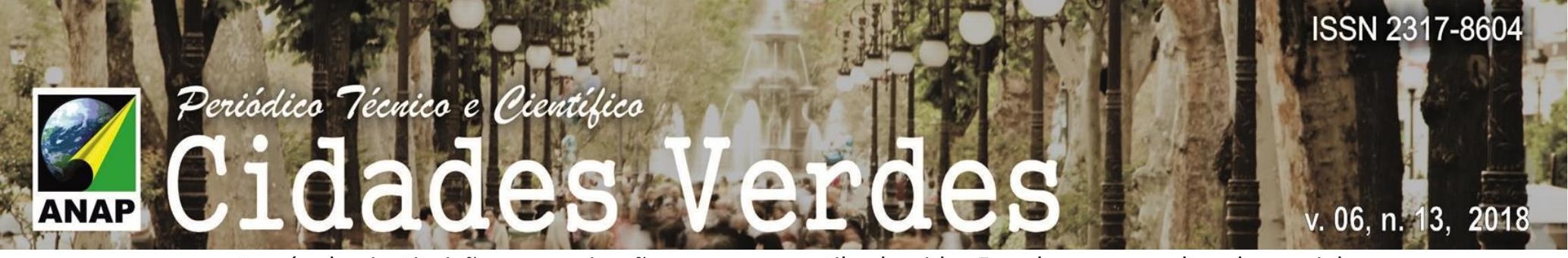

através das instituições, organizações e no seu estilo de vida. Essa bagagem cultural e social dos migrantes adaptou-se ao meio, às limitações do relativo isolamento percebido no período no extremo oeste catarinense, fazendo com que os sujeitos construíssem uma nova identidade, com fortes traços herdados das colônias de origem, mas com uma nova dinâmica estrutural.

De maneira geral podemos sintetizar a origem dos colonizadores de Porto Novo sob duas perspectivas. A primeira das famílias imigrantes originárias da Alemanha e de colônias alemãs europeias como da região da Bessarábia, os Deutschrumänen, e do vale do Rio Danúbio na lugoslávia, os Donauschwaben (JUNGBLUT, 2000). Essas famílias deixaram a Europa motivadas por questões econômicas, políticas e territoriais do cenário conturbado das décadas de 1920 e 1930, sendo significativo o número de imigrantes que se estabeleceram em Porto Novo, principalmente por intermédio de agenciadores e de influência dos padres jesuítas e da Volksverein nesses processos imigratórios. A segunda, composta de famílias descendentes da primeira geração de imigrantes alemães do século XIX que se estabeleceram nas colônias velhas do Rio Grande do Sul e de Santa Catarina. Essas famílias já estavam adaptadas ao território e ao clima brasileiro e deixaram suas regiões de origem motivadas principalmente pela questão fundiária e a degradação das relações produtivas, pela escassez de terras e limitações produtivas (ROCHE, 1969). Além disso, muitas famílias compraram terras em Porto Novo motivados pela propaganda de prosperidade, fartura territorial, de solo e de riqueza natural, além do atrativo étnico e cultural do catolicismo e da germanidade (MAYER, 2016).

Na concepção de Woortmann (1994) a migração de uma colônia velha para uma colônia nova seria um processo de dispersão que minimizaria a pressão demográfica nas primeiras, "fazendo com que o mesmo processo que produz a colônia nova reproduza a colônia velha" (WOORTMANN, 1994, p. 182). Ou seja, nesse processo migratório se reconfiguram conhecimento e vivências simbólicas que estruturam padrões de vida e de compreensões espaço-temporais.

Fato que se pretende destacar é de que havia uma intencionalidade conjectural em se formatar uma colonização homogênea étnica e cultural no local. Essa preocupação já vinha de longa data e o tema se acalorava entre lideranças católicas do Volksverein, elemento que se fundia na preocupação em constituir laços matrimoniais entre famílias católicas e alemãs, manutenção de costumes e tradições consideradas de índole cristã, relações comunitárias e sociais que conservassem padrões sociais tradicionais em oposição ao padrão moderno e heterogêneo então em voga no Brasil (WERLE, 2011). Essa preocupação com a homogeneidade étnica e confessional direcionou o desenvolvimento da colonização Porto Novo nas primeiras décadas, modelo que acabou caindo em desuso a partir da década de 1950. Mas é preciso destacar de que esse padrão germânico e católico foi determinante na formatação de um sistema cultural, elemento que constituiu a base de identidade germânica presente na cultura local e que se manifestou na produção arquitetônica que se pretende analisar.

\section{A ARQUITETURA ENXAIMEL}

A técnica enxaimel, ou Fachwerk, é um padrão arquitetônico atribuído historicamente às regiões germânicas da Europa central. Segundo Weimer (2005) o Fachwerkbau designa um padrão construtivo centenário, originário da sociedade feudal, em que as paredes são estruturadas por um tramado de madeira onde as peças horizontais, verticais e inclinadas são encaixadas entre si em que os tramos são posteriormente preenchidos com taipa, adobe, pedra, tijolos, etc. O enxaimel original da Europa passou por processos de readaptação e reconfiguração ao longo dos tempos, reflexo da disponibilidade de recursos e das limitações 


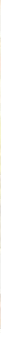

na exploração da madeira para a construção civil. Paulatinamente foram agregados elementos estruturais, como blocos de pedra e no século XIX a alvenaria.

Os partidos gerais do enxaimel europeu são geralmente divididos em alemânico, franco e saxão, elementos que caracterizam a estética e as formas em que são estruturados os elementos. Não é nosso objetivo caracterizar cada uma dessas tipologias, para tanto indicamos a ampla literatura disponível, mas é preciso destacar de que o partido tem uma característica genuína onde o elemento da madeira desempenha um papel fundamental tanto na estrutura, quanto na composição telhado.

A planta única é uma das características das edificações enxaimel, sendo as divisórias internas orquestradas em consonância com as pilastras de sustentação, principalmente nas edificações de maior porte. $O$ elemento central se prostrava em torno do espalho do fogo, geralmente a cozinha, devido às condições climáticas europeias. Na região da Renânia, elemento que nos interessa mais para a análise desse artigo, o enxaimel não se desenvolveu exponencialmente como em outras regiões, devido às históricas turbulências de fronteira e de instabilidades econômicas.

Diversos elementos estruturantes compõe a arquitetura enxaimel como os baldrames, os frechais e as tesouras como componentes do telhado, a composição dos esteios e os barrotes para escoras da estrutura. O sistema de treliças que dá estabilidade à estrutura é um elemento caracterizante dessa técnica construtiva. O sistema alemânico, por exemplo, é caracterizado por um afastamento maior dos esteios principais, o que exigia um vigamento horizontal maior. Diferentemente do sistema franco, onde os esteios estão mais próximos e as escoras possuem leves ondulações. Os contraventamentos ocorrem nas três tipologias do enxaimel e oferecem maior estabilidade e rigidez à estrutura (GISLON, 2013). É importante destacar de que o enxaimel não é um estilo, mas sim, uma técnica construtiva.

Para o momento queremos considerar o fato de que esse partido construtivo veio para o Brasil junto com os imigrantes e se manifestou em diversas regiões de colonização germânica. No entanto, é preciso ter ciência de que houve a necessidade da adaptação do sistema construtivo às limitações impostas pelo meio, pela disponibilidade de matéria prima e pelas exigências climáticas. Apesar da ocorrência do frio na Região Sul do Brasil, as altas temperaturas que também ali ocorrem exigiram novos processos arquitetônicos. $O$ fogo e a cozinha como elemento centralizador do padrão europeu perderam relativa significância no Brasil, sendo inicialmente separado dos demais cômodos, principalmente nas colônias velhas. Mais tarde, com a introdução dos fogões esmaltados a cozinha se integra novamente à casa. Outra ocorrência foi a separação da casa do estábulo, do paiol e da oficina de trabalho do agricultor.

Outro elemento agregado no Brasil foi a varanda, devido ao calor e a ocorrência das chuvas tropicais. As paredes da edificação enxaimel geralmente são estruturadas com os tijolos amostra, diferentemente da Alemanha, onde as paredes são preponderantemente caiadas.

É difícil, ou até impossível estabelecer uma tipologia da ocorrência do enxaimel na região de Porto Novo. Primeiro porque o fluxo migratório, apesar de homogêneo em alguns sentidos étnicos e culturais, foi originalmente bem diverso composto de imigrantes natos alemães e de descendentes de segunda ou terceira geração do século XIX. Segundo porque as técnicas construtivas tiveram que ser adaptadas as necessidades e limitações locais, principalmente no que concerne à disponibilidade de materiais. Diante disso, o que se pode afirmar é de que o enxaimel local, devido às adaptações necessárias, aos materiais utilizados, à disposição dos espaços acabou por constituir uma característica própria e genuína. 


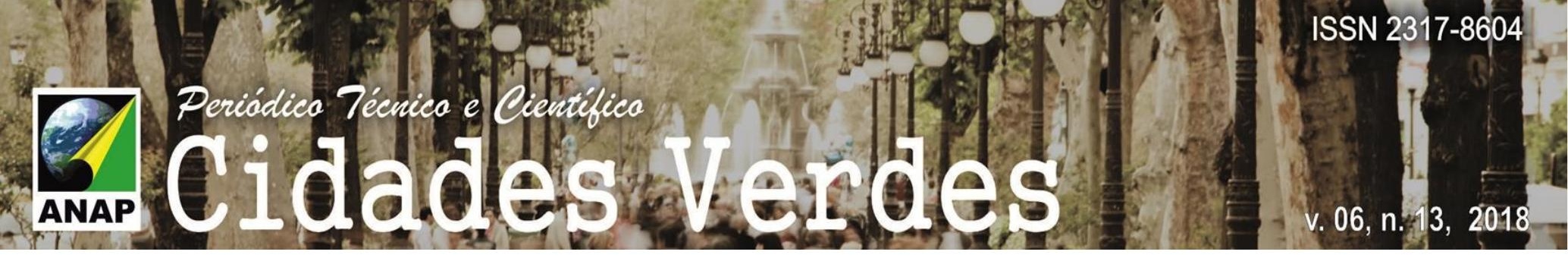

\section{BREVE HISTÓRICO DA EDIFICAÇÃO}

A edificação foi construída no ano de 1936, sendo que o local nas primeiras décadas de colonização era região de chácara, onde a família desenvolvia atividades agrícolas bem como, mantinha um estabelecimento comercial. Nesse sentido, é importante frisar de que a edificação atendeu a duas demandas funcionais no seu princípio: como residência e como estabelecimento comercial.

A estrutura originalmente era autoportante, sendo que na parte frontal funcionava o comércio da família Werlang e aos fundos havia a cozinha. Os cômodos para dormitórios estavam localizados no pavimento superior, o sótão, ou em alemão Speiger. O banheiro e a área de serviço ficavam aos fundos do terreno, sem ligação estrutural com a edificação residencial. $\mathrm{Na}$ Imagem 01 podemos observar uma fotografia da década de 1940 em que somente existe a uma pequena sacada frontal, sem a varanda que atualmente existe.

Imagem 01: Família Werlang na década de 1940..

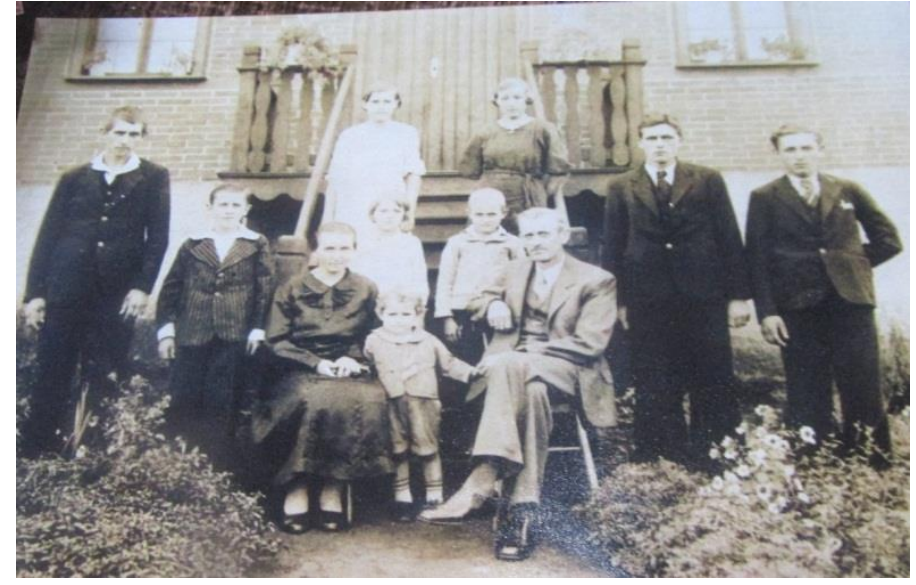

Fonte: Arquivo da Família Werlang

Originalmente a estrutura em madeira da edificação era pintada de verde. Na parede interna, havia uma mescla de cores destoantes: na parte inferior uma faixa em verde e na superior uma faixa em amarelo, separadas por uma linha sinuosa em vermelho. Anos mais tarde, não há especificação exata, foi feito reboco na parede interna.

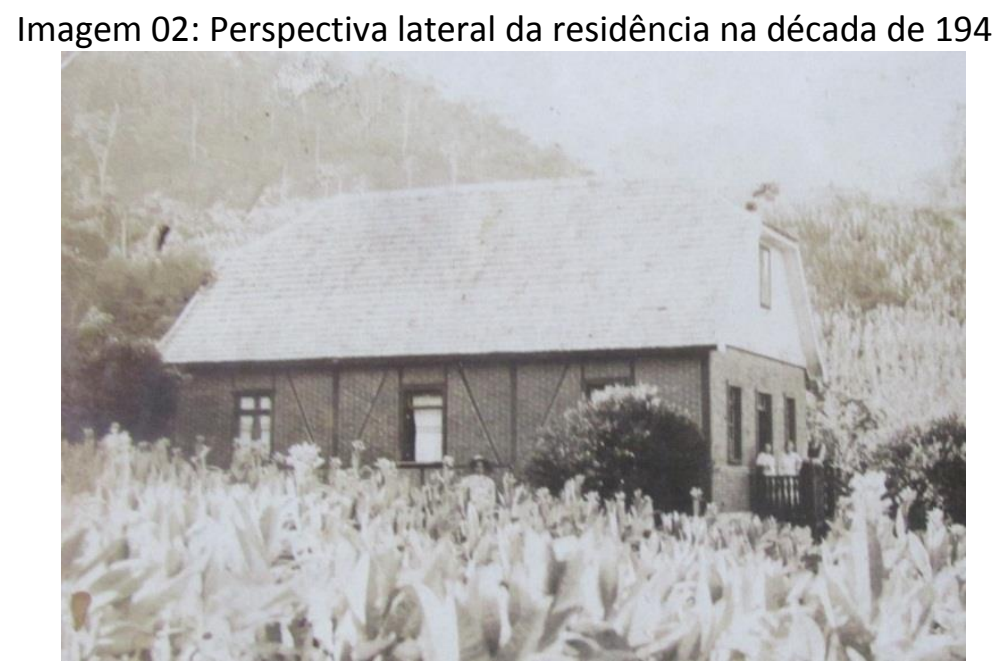




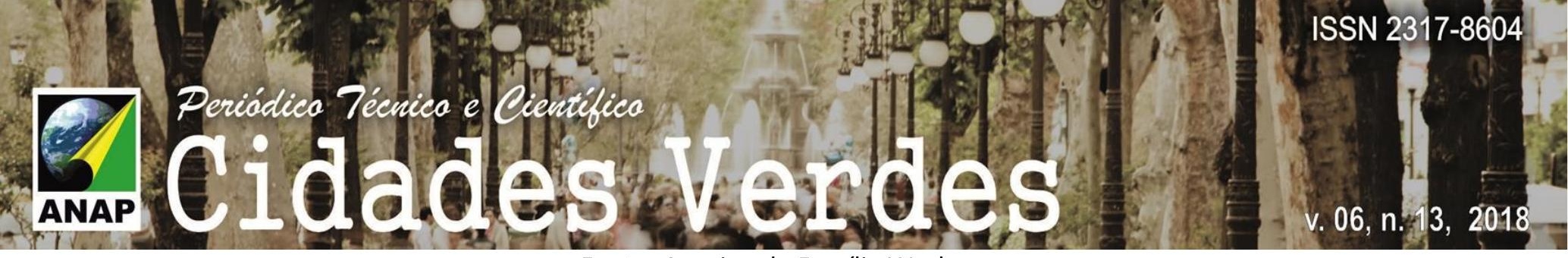

Fonte: Arquivo da Família Werlang

\section{A LOCALIZAÇÃO ATUAL NA PAISAGEM URBANA}

Atualmente a edificação se insere no perímetro urbano da cidade de Itapiranga. Localizada no Bairro Centro, na Rua São José, número 550. No cadastro de imóveis da Prefeitura Municipal de Itapiranga, registrado pelo número 417, o lote urbano 51 consta de uma testada principal de 17 metros e profundidade de 32 metros. No registro consta também uma área construída de $157 \mathrm{~m}^{2}$.

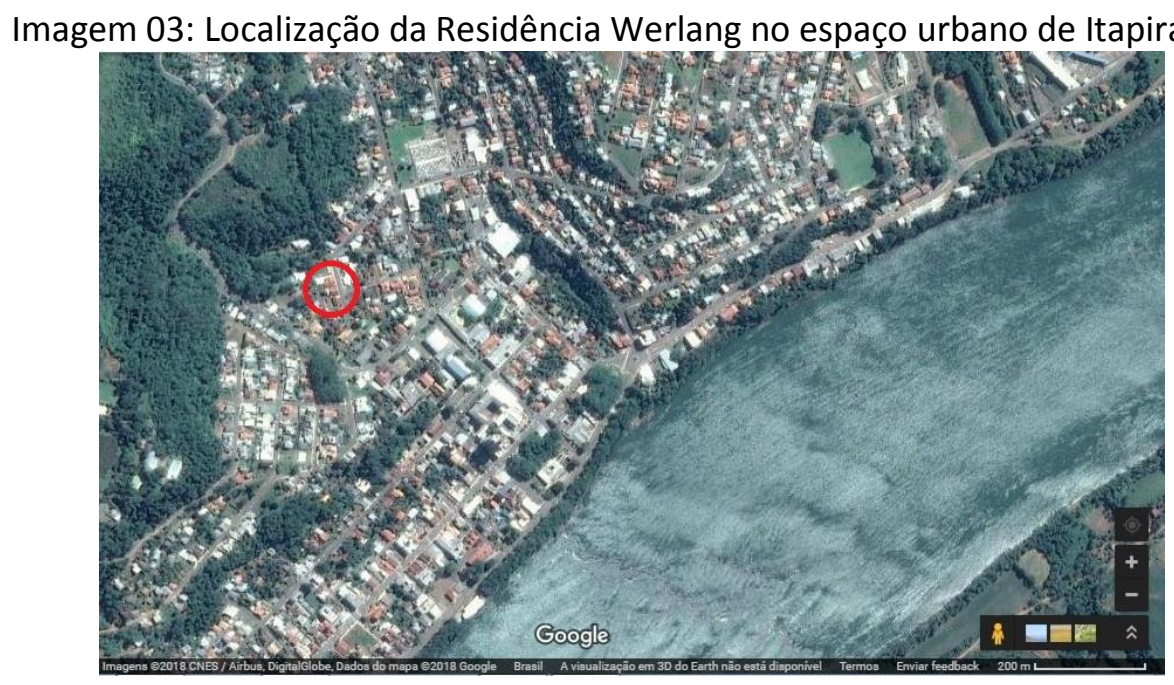

Fonte: Google Maps. Adaptado pelos autores.

\section{A RELEVÂNCIA PATRIMONIAL DO ENXAIMEL}

O conceito de preservação está relacionado mais a uma atitude de preservação, é como uma consciência, que pode pertencer tanto a uma pessoa, um grupo ou uma instituição, com o principal objetivo de proteção ao patrimônio. Trata-se, portanto, da manutenção de um bem no estado físico em que se encontra, tendo como objetivo realizar a prevenção da deterioração e danos e desacelerar o processo de degradação, visando prolongar e salvaguardar o patrimônio cultural. Preservar nunca deve ser considerado um empecilho, mas uma forma de garantir às gerações futuras um passado, uma vez que nossas cidades estão envelhecendo e precisamos compreender que o novo e o antigo devem permanecer juntos, e que um não deve suplantar o outro. Pensar em patrimônio vai além das paredes, dos quintais ou das fronteiras geográficas, patrimônio inclui costumes, sabores e saberes, não contemplando apenas as edificações e monumentos históricos.

O sentido de se preservar está relacionado diretamente ao legado para as futuras gerações, aos registros que são capazes de propiciar a compreensão da história para seus descendentes, uma vez que cada pessoa é parte do todo, da comunidade em que vive e nela constrói, juntamente com os demais, a história de uma sociedade, através dos produtos criados e das intervenções com o meio ambiente. A descaracterização ou destruição dos bens herdados das gerações passadas promovem a ruptura dessa corrente de conhecimento, levando-nos, 


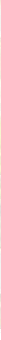

provavelmente, a repetir constantemente experiências já vividas. A preservação também ganha nova força em conjunto com a questão da sustentabilidade, da chamada consciência verde, uma vez que, a partir do momento que um bem é preservado, através do reuso de uma edificação, por exemplo, o impacto ambiental provocado pela produção de bens é reduzido, inclusive no que diz respeito ao consumo de energia e matéria necessária para a produção de uma nova edificação.

Patrimônio, portanto tem alma, tem vida, tem gente, costumes e saberes, é memória e construção, é documento e cultura. Patrimônio material e imaterial não são elementos separados, tudo que é material no patrimônio tem uma relação com algo imaterial. Hoje a concepção mais recente de preservação do patrimônio construído permite uma nova vida para as construções, uma nova função, aliada a sustentabilidade. Assim, preservar o patrimônio cultural de uma cidade é manter as marcas de sua história no tempo, possibilitando, com isso, a construção e reconhecimento das identidades. Trata-se de memória relembrada, capaz de resgatar do esquecimento acontecimentos significativos para a sobrevivência de um grupo, de sua cultura, folclore e etnia. Essa consciência histórica se reconstrói sobre um fundo de esquecimento, pois segundo Tedesco (2011, p. 106) o passado não pode ser recordado por inteiro, e nem da mesma forma em que foi vivido; a memória não tem essa capacidade de congelamento e cristalização.

\section{ESTUDO DA RESIDÊNCIA WERLANG: CARACTERIZAÇÃO TIPOLÓGICA}

A residência Werlang possui um bom estado de conservação com destaque para as linhas horizontais, verticais e diagonais oriundas do madeiramento aparente da estrutura, aspecto arquitetônico que define a edificação juntamente com a cobertura e o sistema construtivo enxaimel, como vemos na Imagem 04.

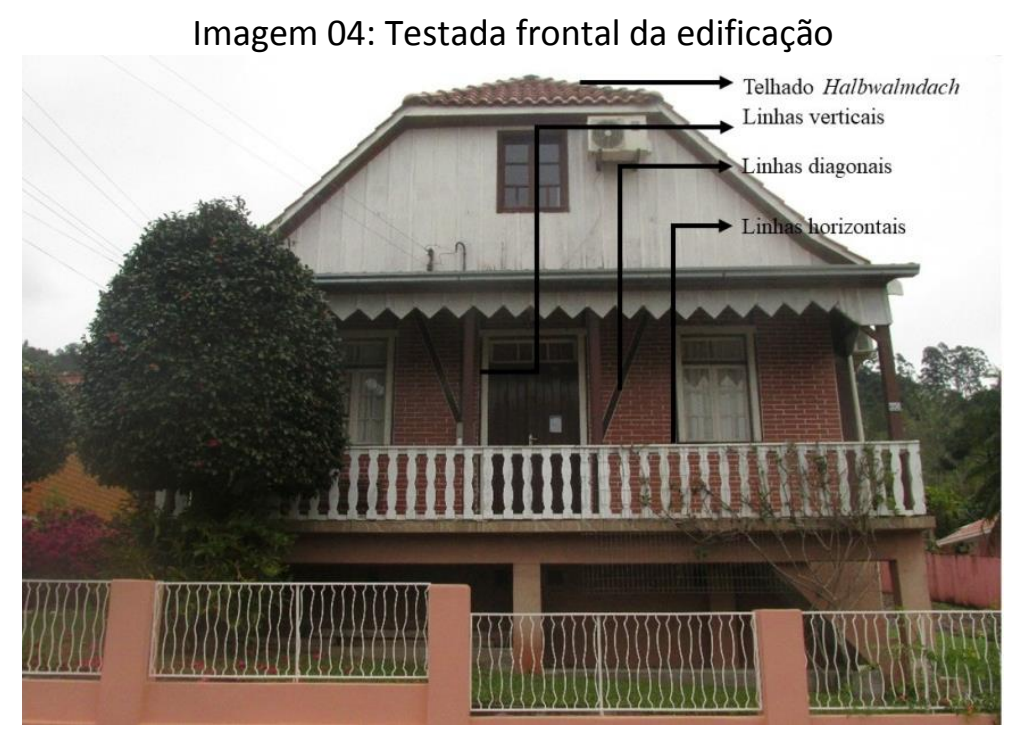

Fonte: Autores (2018)

A base da sua estrutura é composta por tijolos até uma altura de 1,85 metros no seu ponto mais alto, que posteriormente recebeu uma camada de reboco/emboço que consiste no lançamento da argamassa com a utilização da colher de pedreiro, técnica usada atualmente. 0 revestimento final resulta um acabamento texturizado e de considerável valor estético. 


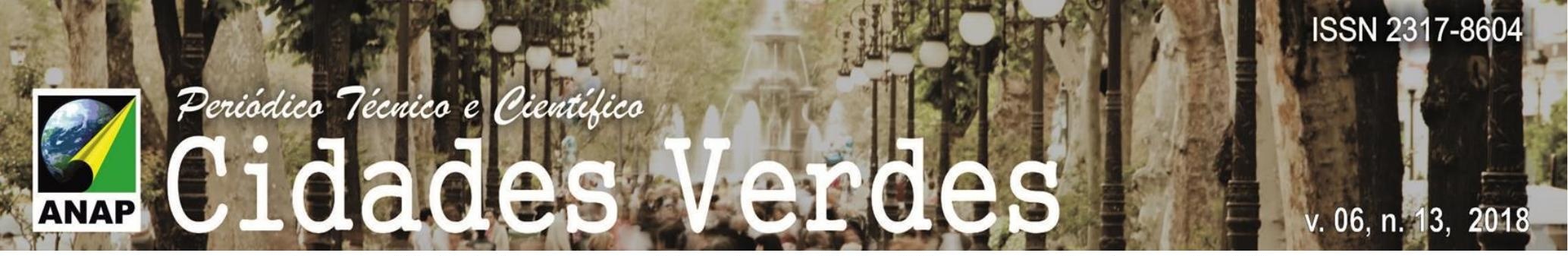

Imagem 05: Detalhe do preenchimento com tijolos (A) e numeração de encaixe (B).
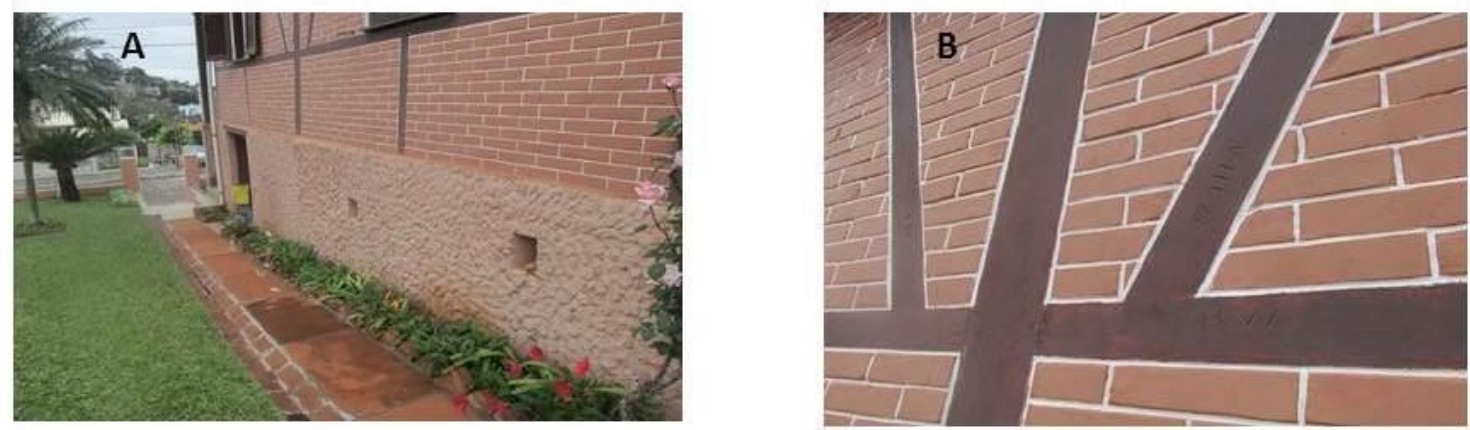

Fonte: Autores (2018)

A base da residência é composta por blocos de pedra, o que garante uma durabilidade maior à edificação, principalmente no que concerne ao condicionante climático, visto que em Itapiranga o inverno é muito úmido.

A estrutura é formada por madeira da espécie Araucária. Os barrotes possuem espessuras de $12 \mathrm{~cm} \times 12$, sendo que os peitoris na linha horizontal se encaixam com os esteios em linha vertical e as vergas em diagonal. Segundo Weimer (2005) logo após as peças estarem devidamente encaixadas as marcações eram realizadas, para que todas as peças pudessem ser identificadas, sendo que essa denominação poderia ser realiza na parte interna ou externa, seguindo geralmente um numeral romano indicando a posição da peça na respectiva parede.

$\mathrm{Na}$ Imagem 09 podemos observar que os carpinteiros utilizaram desta técnica para as peças da parede lateral da residência formando assim, dois conjuntos de numerações. Na época geralmente as residências eram de formatos retangulares, assim três lados possuíam marcação e o restante das peças era para o lado remanescente. Ainda, cada carpinteiro possuía um método de marcação, geralmente com a utilização do formão.

Embora houvesse muitas adaptações no sistema construtivo enxaimel devido aos materiais e clima encontrado no Brasil, a composição preserva muitos elementos da arquitetura enxaimel germânica.

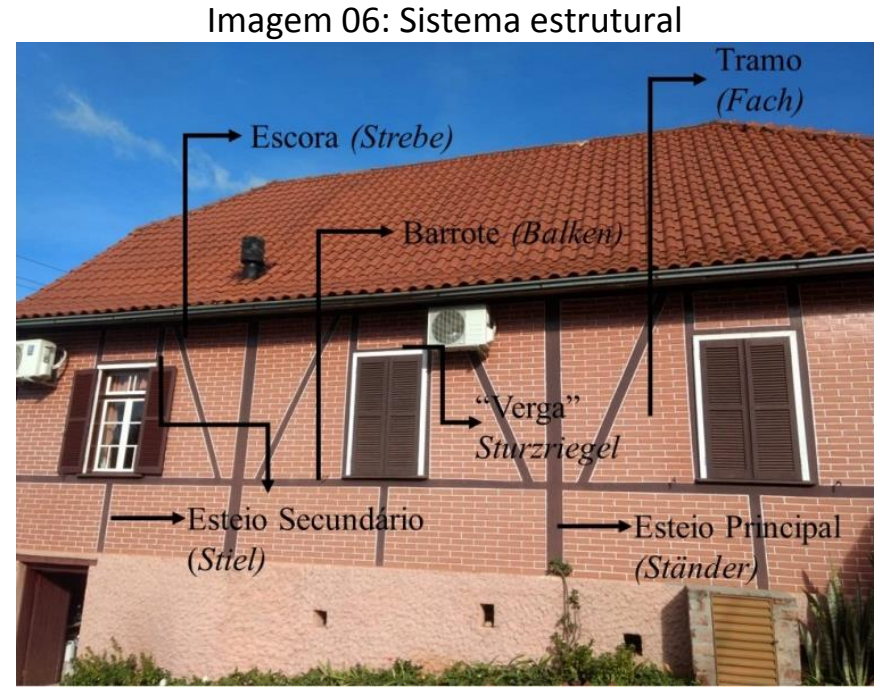

Fonte: Autores (2018)

As paredes internas do primeiro pavimento são todas em madeira, assim como o piso, ambos de Araucária, sendo que foi necessária a substituição do assoalho nos ambientes da cozinha e 


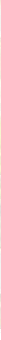

da sala de jantar. Os demais ambientes da residência encontram-se muito bem conservados e preservados conforme podemos observar em imagem 07.

Imagem 07: Piso e paredes de madeira (A) e detalhe da escada interna (B)
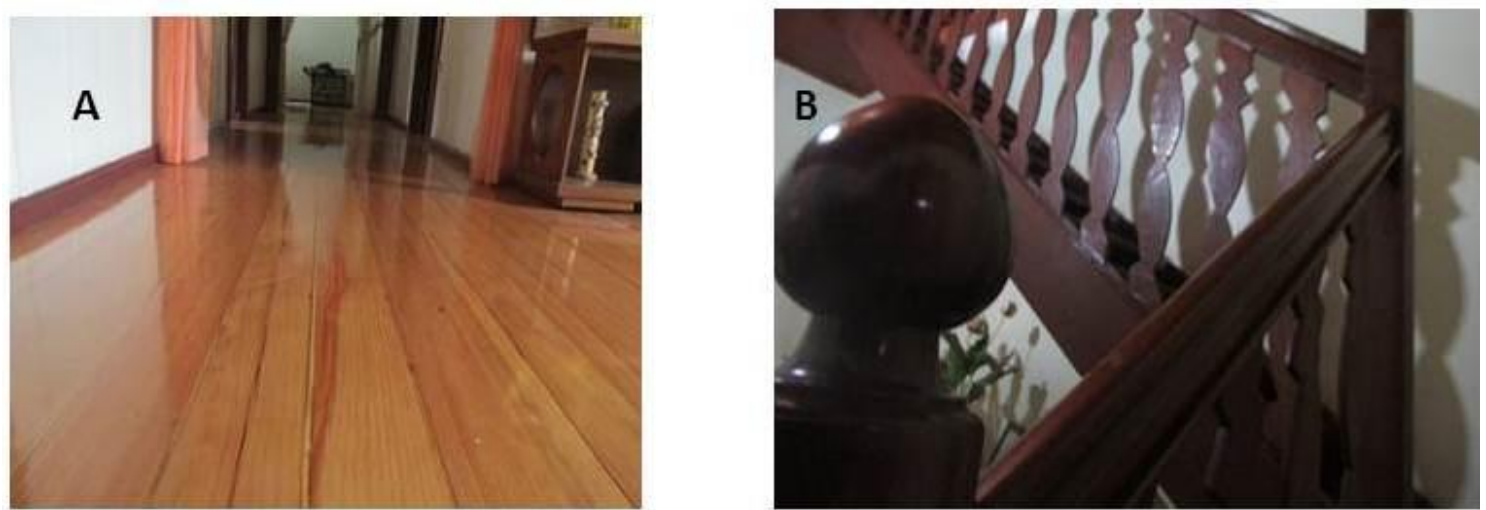

Fonte: Autores (2018)

Já as paredes externas em sua face interna receberam recebo com argamassa e pintura devido a algumas patologias constatadas pelos proprietários, no entanto, com o reboco de argamassa houve um aumento da temperatura ambiente dentro do local, o que exigiu um tratamento térmico com climatizadores.

Como inicialmente a residência servia de comércio na parte frontal do primeiro pavimento, a parte social da casa se localizava aos fundos e os dormitórios se localizavam no segundo pavimento. $O$ banheiro se encontrava afastado da edificação e o pavimento subsolo não era utilizado.

O tipo de telhado é do modelo Halbwalmdach ou então "metade de telhado de quatro águas", seguido de uma estrutura de telhado atirantado Kehbalkensparrendach. Ressalta-se ainda que o barrote Dachbalken está sobre o tabuado (assoalho) do pavimento superior, uma vez que, se procura aproveitar o espaço disponível na cobertura.

Atualmente o telhado é composto por telhas do tipo americanas, que possuem capa e canal na mesma peça, uma vez que, as antigas telhas schindle de madeira apodreceram e houve a necessidade de serem substituídas, sendo necessária ainda a utilização de mantas térmicas devido ao calor no segundo pavimento. A inclinação do telhado é de aproximadamente $65 \%$ nas duas aguas maiores (laterais) e $45 \%$ nas menores (frontal e posterior). A varanda coberta possui uma inclinação de $45 \%$ e conta com o madeiramento aparente. Foram agregados calhas de aço galvanizado nas laterais e na água da varanda além de serem mantidos os espelhos da parte frontal do telhado.

\section{CONCLUSÃO}

A discussão acerca da dimensão do patrimônio histórico envolve uma compreensão dos determinantes da identidade que caracterizam determinada cultura e sua relação com o espaço. Dessa forma, compreender a arquitetura como uma manifestação da identidade é dar um valor simbólico às edificações presentes nas paisagens locais.

Nesse sentido, pretendeu-se relacionar a identidade germânica presente historicamente na colonização de Itapiranga com a manifestação da arquitetura enxaimel no município. Essa constatação simboliza a relevância das práticas de conservação das manifestações arquitetônicas coloniais, que fazem parte da história e consequentemente da identidade das pessoas que habitam esse espaço. 
